\title{
Patients' Subjective Interpretation of Risks Offered in Genetic Counselling
}

\author{
J. H. PEARN \\ MRC Clinical Genetics Unit, Institute of Child Health, 30 Guilford Street, London WC1N 1EH
}

One essential part of the genetic counselling interview is the communication to patients of the recurrence risks to relatives, usually to future children. In the majority of cases a more or less quantifiable mathematical risk can be given. Follow-up studies (Roberts, 1962; Carter, 1967; Carter et al, 1971; Smith, Holloway, and Emery, 1971) have shown that parents generally act in a way determined by whether they fall into high risk or low risk groups but many exceptions occur.

All theories of decision making under risk contain two basic components (Tversky, 1967); these are (1) the desirability of the outcome to the individual or individuals concerned and (2) the perceived likelihood of the desirable result eventuating. In the genetic context the former of these two factors-the desire for children and in particular healthy children -is a basic human characteristic which is predetermined by cultural and personal influences (Itkin, 1952). It is fixed long before the specific genetic status of the individual is suspected or, in the case of dominance, before the significance of the latter to future children is appreciated. Whether or not 'at risk' parents satisfy this universal desire and act to have children depends very largely on the subjective interpretation of odds given to them.

Rational decision making by humans under risk has been the subject of extensive laboratory investigation (Ziller, 1957; Phillips and Edwards, 1966; Slovic, 1966; Beach and Phillips, 1967; Howell, 1967; Meyer, 1967; Roby, 1967; Tversky, 1967; Lieblich, 1968; Alker, 1969; Steiner, 1970). However, studies of risk taking propensities and attitudes to odds in clinical situations have been confined almost exclusively to such select groups as mental retardates, alcoholics and cases of attempted suicide (McManis and Bell, 1968/1969; Rule and Besier, 1970; and Kennedy, Phanjoo, and Shekim, 1971).

Received 18 December 1972.
Follow-up studies of a large general group of parents who have attended genetic counselling clinics (Carter et al, 1971; Smith et al, 1971) and surveys of special genetic risk groups (Pearn and Wilson, 1973) perhaps offer unique opportunities to study patients' subjective interpretation of risks in the clinical, as opposed to the psychological laboratory situation. Both types of approach offer complementary evidence of the way in which the normal individual considers personal risk.

The personal subjective interpretation of odds is one of the two major influences which shape the decisions parents ultimately make in what can be regarded as a clinical gambling situation confronting normal people. One makes no judgement of these subjective influences or decisions resulting therefrom; rather, a knowledge of such influences is helpful when advice, prognosis, and counsel is being given. It is the purpose of this paper to discuss these factors which shape the individual's subjective interpretation of mathematical risk given to him in the genetic context.

\section{The Meaning of Odds to Different Patients}

The concepts of probability and the quantitative expression of risks are very old. Examples of dice and games of mathematical risk are known from as early as 2600 BC. It is common experience that in any situation involving odds (eg, football pools) that the same objective odds appreciated by intelligent individuals result in different degrees of acceptance or rejection of the bet or wager. Recognizing the variability in the subjective interpretation of a specific mathematical risk Ramsey (1931) wrote that 'it is not enough to measure probability; in order to apportion correctly our belief to the probability we must also be able to measure our belief'.

It is clear from both every day and clinical observation that people differ widely in their attitude to risk. Such variation probably forms a continuous spectrum varying from extreme cautiousness 
to recklessness, but attempts to quantify the propensity for risk taking and the individual's attitude to odds have not yet been successful. Although one cannot measure such 'risk thresholds' (Steiner, 1970) in practice, it is nevertheless desirable for a genetic counsellor to make some estimate of the patient's interpretation of risk figures when such are given.

It has been suggested that although subjective probabilities cannot be measured directly they can be inferred from behaviour (Beach and Phillips, 1967). This is not always applicable, however, as in the genetic situation at least the decision whether or not to have further children may not be fulfilled due to extraneous factors such as infertility on the one hand or 'unplanned' pregnancies on the other (Carter et al, 1971). Also, it has been shown that riskiness in abstract judgement is not the equivalent of situations involving real-life risk taking (Rettig, 1966).

The ability of humans to use probabilistic information may be very good (Roberts, 1962; Roby, 1967) but tends to be degraded by rather widespread biases such as conservatism; conservatism in this sense being defined as a reluctance to formulate either very high or very low subjective interpretations of objective risks. In other words subjective probabilities generally avoid extreme values. That humans universally tend towards conservatism in estimating probability or risk is generally accepted (Preston and Baratta, 1948; Phillips and Edwards, 1966; Howell, 1967) but the degree of individual variation of this propensity in the clinical situation is not known, and probably cannot be accurately measured.

Some tenets of formal logic are interesting in this context. If a rare event occurs (eg, a 100 to 1 chance), its occurrence in no way invalidates the fact that it was improbable. However, patients who have been unlucky may regard themselves as specially vulnerable, to be subject to a 'loading' factor as it were, which is specific for them. It is desirable for both doctor and patient to recognize when this loading factor remains truly absent, as in the case of parents heterozygous for a recessive gene who have had the bad luck say to have three out of three affected children; or in the case where successive bad luck indicates that true loading might be present, for example in the case of lesions transmitted by polygenic inheritance. In such cases the odds of recurrence objectively increase after each lost genetic gamble (Carter, 1969a).

\section{Presentation of Risk Figures}

The manner in which risk figures are expressed is important and may have a significant influence on the patient's interpretation of his risk. The same objective risk for known heterozygotes for a recessive gene may be expressed as either a 1 in 4 risk of the disease occurring, or alternatively as a 3 to 1 chance that the child will be normal. In some genetic situations the deliberate use of this type of approach may be a legitimate example of attempting to produce a directed interpretation of the risk. This type of encouraging approach is probably best used to reinforce manifest tendencies or attitudes which are already present. For example a couple may so desperately want a living child of their own after having lost several children from a fatal recessive disease (eg, infantile spinal muscular atrophy) that they are going to go ahead in spite of the objectively high risks of recurrence involved. If it is pointed out that they have a 3 to 1 chance of a normal child, they may obtain some reassurance and comfort in what is always a very worrying period of waiting.

It is generally accepted that prior discussion of a risk situation leads to an increased willingness on the part of the average discussant to take greater risks (Rettig, 1966; Chandler and Rabow, 1969; Horne, 1970). Whether or not the discussion that occurs during genetic counselling also produces this 'riskyshift' (Horne, 1970) is not known, but it would be surprising if this influence were absent, albeit masked by stronger perhaps opposing influences. Chandler and Rabow (1969) suggest that irrespective of whether an individual chooses a risky or a cautious gamble in any risk situation there is always group support for him. The degree of support, however, is related to the circumstances involved and the specific problem under discussion. If the group providing support is the discussant's own family, then this 'risky-shift' is minimal.

\section{Anticipation of the Risk Odds}

When a parent or relative consults a geneticist, they usually have some anticipated idea about the likelihood of disease recurrence. Some preconceived concept of risk has usually already been formulated. This prior belief may or may not be correct, but it serves as an unconscious reference point for the professionally supplied risk, and so modifies the patient's final subjective interpretation of the latter.

This phenomenon is not uncommon, particularly in the case of misinformed parents who have two or more children affected with a dominant condition. In this situation a number of parents fear that all future children must be affected; when told that the risk is $50 \%$ only (and not $100 \%$ ) they may be quite delighted. The antithesis of this situation is the case where parents present expecting a very 
low risk (say 1 in 100) and are given a risk of greater magnitude (say 1 in 25). Although still probably a low risk this may be subjectively interpreted as one of a greater order of magnitude. In practice, probably the majority of patients leave a genetic counselling clinic furnished with risk figures smaller than those they vaguely perceived before consultation, although this also varies with the particular genetic counsellor.

The degree of stress engendered by a family genetic problem may be important in this context. Lieblich (1968) has shown experimentally with humans that personal stress reduces the tendency to take risks. This may be due to a changed attitude to the 'prize' (eg, a healthy child) attainable in the gambles involved, but in the case of a family genetically at risk it is more likely to be due to prior attitudinal fixation of presumed risks before professional counsel is sought or given.

\section{Nature of the Outcome if Risk Eventuates}

This is perhaps the most obvious factor influencing the subjective interpretation of odds. Very few of us would contemplate the thrills of Russian roulette with its 1 in 6 risks of disaster ( 5 to 1 against) but most of us cheerfully invest in a 100 to 1 chocolate wheel at the annual local fair. In each case the probability of the feature result occurring is fixed (assuming a skilled gunsmith and an honest fairman) but the implications of a loss make the 1 in 6 chance of death far too high for most of us even to contemplate, and the 100 to 1 chance of a lost shilling quite acceptable.

This theme has two important genetic overtones. First, it implies that parents can assess specific genetic risks only if they are informed of the sequelae in all their implications. This is often most appropriately undertaken by their own general practitioner. In some exceptional cases (eg, when a woman is in late pregnancy) it would be totally inappropriate to raise these issues. Again, when parents have obviously made an irreversible decision to have (or not to have) further children it may not be appropriate to dwell on this point. These exceptions aside, objective odds are interpreted quite differently by different parents who are informed of the full implications of a lost gamble.

Experimentally, it is known that a knowledge of the consequences of a decision involving risk significantly increases the optimality of choice, at least in sequential risk situations (Meyer, 1967) and this finding is probably directly applicable to genetic counselling. Parents are sometimes prepared to take higher risks if a child who is affected will die in infancy (Murphy, 1968; Carter, 1969a and b). In the case of spinal muscular atrophy (SMA) for example the same objective 1 in 4 recurrence risk tends to be interpreted relatively incautiously by parents who are heterozygotes for the gene for the rapidly progressive infantile form of the disease. In this case it is virtually certain that an affected infant will die within the first 3 years of life (Pearn and Wilson, 1973). For those who carry the gene for chronic spinal muscular atrophy, however, a lost gamble often means caring for an affected child and subsequently an adult for up to 25 years of helpless (physical) existence and the recurrence risk tends to be considered with much greater caution for these very practical reasons. In fact, in this latter type of case it is usual for the genetic gamble to be absolutely rejected by informed parents.

Secondly, it implies that a specific, genetically determined disease can mean different things to different people. The subjective attitude to the disease or lesion itself may be quite at variance with what informed medical opinion would regard as a realistic appraisal. Relatively minor limb defects with cosmetic overtones are examples here. On the other hand some patients regard with considerable equanimity genetic lesions which are of major medical significance. Thus there is a two-stage process involved in the interpretation of risk in this context. First, the patient or parent forms a very subjective personal view of the disease or lesion itself, and then he or she forms a subjective interpretation of the risks for that concept of the disease.

A striking example of this has been seen in the Genetic Counselling Clinic at The Hospital for Sick Children, Great Ormond Street. A woman with both of her two children suffering from coeliac disease came for genetic advice about the risks to further children. A risk of approximately 1 in 10 was given. This turned out to be disappointingly low for the woman in question, and it became obvious that she wanted her next child to have coeliac disease! They were intelligent parents and it transpired that their affected children were doing very well on their diet and the whole domestic microenvironment had adapted superbly to the problems inherent in managing coeliac disease. Both parents also followed the diet, so different cooking schedules were not a problem; there was no gluten-containing food in the house to pose a temptation to the affected children. The parents felt, however, that if a noncoeliac child was born the whole domestic equilibrium would be in turmoil, and the physical and mental expectations of the two children already doing very well could be jeopardized.

For parents seeking advice, both the above themes are understood by parents who have had representa- 
tive past experience of the specific problems about which they are concerned on genetic grounds. The influence of past experience is very important in the subjective interpretation of future risks if a gamble is being contemplated. In test situations past experience has been shown to lead to a more realistic assessment of mathematical odds (Beach and Phillips, 1967). Furthermore, even in the case of intelligent parents it has been found that the individual learns to make optimal choices in a betting situation only after a number of such trials; rational decision making under risk is known to be illogical especially for random or single gambles (Meyer, 1967). This is probably applicable to the current genetic situation where family sizes tend to be small.

Considerable study of the objective interpretation of mathematical odds in sequential risk-involved situations has been undertaken (Beach and Swensson, 1967; Roby, 1967; Alker, 1969). This is probably directly applicable to genetic counselling also. For example if two successive children have been born affected by a genetically determined disease such as spina bifida or cleft lip, the objective risks of recurrence are of the order of 1 in 8 to 1 in 10; the 'run' itself of bad luck, however, may cause the parents subjectively to interpret the 1 in 8 recurrence risk in more cautious terms than they would otherwise do. There has been a similar example in the attitudes of parents who have had a run of bad luck losing each of their four infants from Werdnig-Hoffmann disease, and other examples are recorded (Roberts, 1962). The psychological dependency on a run of good or bad luck is very strong and such 'run dependency' may influence further risks taken even when strong counsel is given to highly intelligent test subjects about its mathematical fallacy (Beach and Swensson, 1967).

An antithetical example of the same process is not infrequently seen in the context of sex-linked inheritance using Bayesian methods of counselling (Murphy, 1968; Nicholls and Stark, 1971). Consider the case of a mother known on prior pedigree evidence to have a 1 in 2 chance of carrying a sexlinked gene. Following the birth of two out of two normal boys to her, her objective risks of having a further child affected fall to 1 in 20 . However, after the run of good luck she may not wish 'to tempt fate further' even although her objective risks are now relatively low (other factors such as attitudes to family size etc are obviously important here also). This phenomenon is probably related to the psychological phenomenon of 'feedback' in risk taking situations (Alker, 1969) where changes in risk taking strategy have been shown to occur depending on results in a sequential risk-involved test situation.

\section{Personality of the Patient or Parents}

Basic personality type is known to be important in the interpretation of odds, although the specific factors underlying this are not fully understood (Moran, 1970). With the proviso that patients who present to a genetic counselling clinic tend to be of relatively high intelligence (Carter et al, 1971) the full range of personality types is encountered in counselling and genetic research work, and a consideration of some of the factors which summate to form personality is therefore appropriate.

The pessimistic person tends to increase his view of risk; 'just my luck' implies that although a general risk might be relatively low the subject believes that for him or her as a particular individual the risk is somehow, almost in a metaphysical way, greatly increased. In this case it is particularly desirable to stress the random nature of genetic disease and to note that if harmful genes are circulating in a population, someone is bound to get them ( $\mathrm{Li}, 1961)$. The antithesis of this person, the optimist, believes that although he is subject to a general risk somehow his real personal risk is much less-'it can't happen to me'. It is known that subjects who consider themselves to be passive recipients vulnerable to their total environment ('externally-controlled subjects') tend to accept higher risk gambles than people who regard themselves as basically capable of environmental manipulation (Liverant and Scodel, 1960).

Alker (1969) has demonstrated that there is a basic distinction in the attitude to risk between a person who is achievement-orientated when compared with the failure-threatened subject. In the genetic context, a parent who is weighing up the gains of having a normal child against the realities of having an affected one would thus be influenced in these subjective risk interpretations depending on which of these two basic factors is inherent in his or her personality.

\section{Interpretation of Individual Risk against the General Risk Background}

The subjective interpretation of genetic risk is modified by a knowledge of the general risk background. The additional specific risk can thus be put into perspective. English parents who have had a child with spina bifida for example may be given a specific recurrence risk of approximately 1 in 50 for a subsequently affected living child (Carter, 1969a). Parents tend to be relieved (and presumably view their specific risk with less alarm) when told that approximately 1 in 50 of all living newborn infants have an abnormality of one type or another. The 
general risk background is also a factor for couples contemplating artificial donor insemination (AID) for a genetic disorder. Here, if couples decide to go ahead with AID they have formulated a subjective interpretation of the general risk and have seen their own risk in relation to it.

Some parents consider, correctly or incorrectly, that their own family trees are heavily biased in the direction of genetic disease. In such cases the parents have two forms of general risk against which to compare their own specific risk for a future child. Their attitudes to their own specific risk may be modified by their belonging to an extended family tree in which they believe genetic disease is common. This latter situation is probably akin to an extension of the theory of sub-cultural gambling which arises if an individual's background (his micro-environmental norm) is one in which risktaking is a part of life (Moran, 1970).

\section{Temporal Factors}

All of the different modifying factors mentioned above may vary with the individual parent or patient from time to time. Our attitudes to risk vary with our changing moods (Steiner, 1970), we are better informed at some times than at others, and our propensity for rational risk taking certainly varies according to different situational backgrounds. Kallmann (1965) reports that it is not uncommon for even highly intelligent individuals to regress temporarily to 'immature levels' of emotion and thought when confronted with specific genetic risk. Genetic counselling has to be given at the right time for it to be logically interpreted by the individual for whom it is directed (C. O. Carter, personal communication).

It has been shown experimentally that for humans confronted with sequential risk situations early experience is important, and that there is a disproportionate weighting of early evidence (Roby, 1967). In the clinical situation of a family with genetic risk to children two opposing influences probably operate here. On the one hand, if a serious chronic genetic disease occurs in a first child, the interpretation of recurrent risks to subsequent children will of course be modified. On the other hand the natural desire for children or for at least one normal child is very great, and will tend to conflict with the disproportionate weighting effect of the first child being affected. In the reverse situation where the parents genetically at risk (eg, in the case of dominance) have the good fortune to have had a number of normal children the disproportionate weighting evidence is probably still operative, but any measurable effect is swamped by the much stronger influences of personality or of cultural dictates concerning family size.

\section{Other Factors}

A number of other phenomena may influence the individual in this attitude to genetic risk situations. Guilt, either normal or pathological, transient or permanent, often intensifies the magnitude of risk perceived by an individual. Parents who feel guilty about congenital malformations in their children (Roberts, 1962) may interpret the objective risks of recurrence much more menacingly than parents who do not have guilty overtones but who have been given the same objective risks of recurrence.

Intelligence is obviously important in the interpretation of odds. Intelligence is probably important in each of the modifying factors discussed above but at the core of the subject lies the individual's ability to appreciate the mathematical symbolism of exact risks, or at least the ability to appreciate relative orders of risk. 'The formulation of a realistic interpretation of odds is dependent on how well subjects are able to use numbers to reflect their actual perception of probabilistic events or degrees of certainty' (Howell, 1967).

Sex differences in attitudes to risk are well known, but in risk situations requiring cooperation between two individuals to maximize returns it has been shown that sex differences are not important (Pilisuk, Skolnick, and Overstreet, 1968). Interestingly, it has been shown that males who are motivationally-determined risk takers are generally dissatisfied when they adopt a conservative strategy (Alker, 1969) and this has obvious medical overtones for marriages which have declined a genetic gamble. In the family situation however it is the male who is usually least motivated for further children so difficulties arising from sex differences in the attitude to accepted or rejected odds probably tend to be minimized.

The author expresses his sincere gratitude to $\mathrm{Dr} C$. O. Carter for help and kindness during the 14 months spent with him in the MRC Clinical Genetics Unit, the Institute of Child Health, London; and for permission to attend the Genetic Counselling Clinic at The Hospital for Sick Children, Great Ormond Street, from which visits the observational content of this paper has been derived. This work was undertaken during the tenure of the Florey Fellowship, The Royal Society, which the author gratefully acknowledges.

\section{REFERENCES}

Alker, H. A. (1969). Rationality and achievement: a comparison of the Atkinson-McClelland and Kogan-Wallach formulations. Fournal of Personality, 37, 207-224. 
Beach, L. R. and Phillips, L. D. (1967). Subjective probabilities inferred from estimates and bets. Fournal of Experimental Psycho$\log y, 75,354-359$.

Beach, L. R. and Swensson, R. G. (1967). Instructions about randomness and run dependency in two-choice learning. fournal of Experimental Psychology, 75, 279-282.

Carter, C. O. (1967). Comments on genetic counselling. In Proceedings of the third International Congress of Human Genetics, ed. by J. F. Crow and J. V. Keel, pp. 97-100. Johns Hopkins Press, Baltimore.

Carter, C. O. (1969a). Genetics of common disorders. British Medical Bulletin, 25, 52-57.

Carter, C. O. (1969b.) Eugenics and Human Hereditary. (The Essex Hall Lecture for 1969). The Lindsey Press, London.

Carter, C. O., Fraser Roberts, J. A., Evans, K. A., and Buck, A. R. (1971). Genetic clinic. A follow-up. Lancet, 1, 281-285.

Chandler, S. and Rabow, J. (1969). Ethnicity and acquaintance as variables in risk-taking. Fournal of Social Psychology, 77, 221-229.

Horne, W. C. (1970). Group influence on ethical risk taking: the inadequacy of two hypotheses. Fournal of Social Psychology, 80, 237-238.

Howell, W. C. (1967). An evaluation of subjective probability in a visual discrimination task. Fournal of Experimental Psychology, 75, 479-486.

Itkin, W. (1952). Some relationships between intra-family attitudes and pre-parental attitudes towards children. Fournal of Genetic Psychology, 80, 221-252.

Kallmann, F. J. (1965). Some aspects of genetic counselling. In Genetics and the Epidemiology of Chronic Diseases, ed. by J. V. Nee, M. W. Shaw, and W. J. Schull, pp. 387-388. US Public Health Service Publication no. 1163, Washington.

Kennedy, P. F., Phanjoo, A. L., and Shekim, W. O. (1971). Risktaking in the lives of parasuicides (attempted suicides). British Fournal of Psychiatry, 119, 281-286.

Li, C. C. (1961). Human Genetics. Principles and Methods, pp. 180-181. McGraw-Hill, New York.

Lieblich, A. (1968). The effects of stress and the motivation to succeed on test-risk. Fournal of Personality, 36, 608-615.

Liverant, S. and Scodel, A. (1960). Internal and external control as determinants of decision making under conditions of risk. Psychological Reports, 7, 59-67.

McManis, D. L. and Bell, D. R. (1968/1969). Risk-taking by reward-seeking, punishment-avoiding, or mixed-orientation retardates. American fournal of Mental Deficiency, 73, 267-272.
Meyer, D. E. (1967). Differential effects of knowledge of results and monetary reward upon optimal choice behaviour under risk fournal of Experimental Psychology, 75, 520-524.

Moran, E. (1970). Clinical and social aspects of risk-taking. Proceedings of the Royal Society of Medicine, 63, 1273-1277.

Murphy, E. A. (1968). The rationale of genetic counseling fournal of Pediatrics, 72, 121-130.

Nicholls, E. M. and Stark, A. E. (1971). Bayes' theorem. Medical fournal of Australia, 2, 1335-1339.

Pearn, J. H. and Wilson, J. (1973). Acute Werdnig-Hoffmann disease: acute infantile spinal muscular atrophy. Archives of Disease in Childhood, 48, 425-430.

Phillips, L. D. and Edwards, W. (1966). Conservatism in a simple probability inference task. Fournal of Experimental Psychology, 72, 346-354.

Pilisuk, M., Skolnick, P., and Overstreet, E. (1968). Predicting co-operation from the two sexes in a conflict simulation. Fournal of Personality and Social Psychology, 10, 35-43.

Preston, M. G. and Baratta, P. (1948). An experimental study of the auction-value of an uncertain outcome. American fournal of Psychology, 61, 183-193.

Ramsey, F. P. (1931). Degrees of belief. In The Foundation of Mathematics and other Logical Essays, ed. by R. B. Braithwaite, pp. 166-184. Kegan Paul Trench Trubner, London.

Rettig, S. (1966). Group discussion and predicted ethical risk taking. Fournal of Personality and Social Psychology, 3, 629-633.

Roberts, J. A. F. (1962). Genetic prognosis. British Medical fournal, 1, 587-592.

Roby, T. B. (1967). Belief states and sequential evidence. Fournal of Experimental Psychology, 75, 236-245.

Rule, B. G. and Besier, D. P. (1970). Level of risk advocated by alcoholics. Psychological Reports, 27, 829-830.

Slovic, P. (1966). Value as a determiner of subjective probability. IEEE Transactions Human Factors in Electronics, 7, 22-28.

Smith, C., Holloway, S., and Emery, A. E. H. (1971). Individuals at risk in families with genetic disease. Fournal of Medical Genetics, 8, 453-459.

Steiner, J. (1970). An experimental study of risk-taking. Proceeding of the Royal Society of Medicine, 63, 1271-1273.

Tversky, A. (1967). Utility theory and additivity analysis of risky choices. Fournal of Experimental Psychology, 75, 27-36.

Ziller, R. C. (1957). A measure of the gambling response-set in objective tests. Psychometrika, 22, 289-292. 